\title{
Vacuum processing of food-a Mini Review
}

\begin{abstract}
Conventional food processing operations such as frying, drying, and blanching which are performed under atmospheric condition sexposures product to high processing temperature. In addition to the potential product contamination from exposure to atmospheric conditions, other challenges/issues include nutrient losses, changes in the product sensory attributes and lengthy processing time. In order to minimize the aforementioned disadvantages, the food industry has adopted novel techniques like vacuum processing for operations such as frying, cooling, drying, packaging etc.
\end{abstract}

Volume 6 Issue 3 - 2018

\author{
Sharanabasava, Menon Rekha Ravindra \\ SRS of ICAR, India
}

Correspondence: Menon Rekha Ravindra, SRS of ICARNDRI, Bangalore, India, Email rekhamn@gmail.com

Received: December 02, 2016 | Published: May 25, 2018

Keywords: food processing, vacuum pressure, standard atmosphere, lacking, food products, vegetables, kiwifruits

\section{Introduction}

The term vacuum is generally used to represent a volume or state of space in which the pressure is considerably less than atmospheric pressure. In the pressure measurement system, normal vacuum pressure is expressed in millimeters of a column of mercury, and 760 millimeters of mercury is designated as 1 standard atmosphere. Another conventional unit of pressure, especially at lower pressure is the Torr, which approximately equals 1 millimetre of mercury. The SI unit for vacuum pressure is Pascal's and standard atmospheric pressure is $101.325 \mathrm{kPa}$. A perfect or absolute vacuum, which denotes a space that is entirely lacking of matter, is basically unrealizable.

\section{Vacuum frying}

Vacuum frying operation is carried out at pressures below atmospheric pressure. Frying changes the color, appearance, texture and product composition; rendering the fried product palatable to the consumer. Vacuum frying has been applied to a wide variety of food products including snacks and treats. A large application of this technology is reported for fruits and vegetables. The latest reports comprise of vacuum frying of apple, apricot, banana, jackfruit, green and gold kiwifruits, carrot, mushroom, potato, shallot, sweet potato and purple yam.

\section{Vacuum frying systems}

A vacuum frying system essentially includes three components, namely a vacuum frying chamber, a refrigerated condenser and a vacuum pump. The vacuum frying chamber is a hermetic vessel facilitated with an oil heater and a frying basket. The frying basket is raised and lowered into the heating medium with a lift rod. The lift rod is connected to a spinner motor that centrifuges the product to eliminate surface oil. The refrigerated condenser traps the steam released during frying and condenses on a cold surface. The vacuum pump provides the required reduced pressures for the process.

Andres-Bello et al. ${ }^{1}$ identified three vacuum frying equipment based on size: laboratory, pilot and industrial scale system and in terms of processing requirements: for batch or continuous processes. The authors have accordingly elaborated on three examples of vacuum frying systems.

Yamsaengsung et al. ${ }^{2}$ used a gas-heated vacuum frying chamber, a water-cooled condenser and a liquid ring vacuum pump to develop a vacuum frying system. The fried product was centrifuged at 450 rpm within the frying chamber. Sothornvit ${ }^{3}$ studied different patterns of vacuum frying system used in processing. He developed a vacuum frying chamber equipped with heated oil from another chamber, a cooling tower type condenser and an oil-sealed vacuum pump. Diamante et al. ${ }^{4}$ used a vacuum frying chamber with a water-cooled condenser cooling tower and liquid ring vacuum pump to vacuum fry jackfruit chips. After frying, the jackfruit chips were centrifuged at atmospheric pressure in a separate machine. Diamante et al. ${ }^{4}$ also reported on vacuum frying of gold kiwifruit slices. The system used consisted of a steam-heated vacuum frying chamber, a water-cooler condenser and an oil-sealed vacuum pump. The fried products were then centrifuged at atmospheric pressure using another unit. Pandey \& Moreira $^{5}$ used a vacuum fried potato chips in a system consisting of an electric-heated vacuum frying chamber, a refrigerated condenser and an oil-sealed vacuum pump. The vacuum fried chips were centrifuged within the chamber at speeds of up to $750 \mathrm{rpm}$.

\section{Advantages of vacuum frying}

Vacuum frying is an alternative way to enhance the quality of fried food products compared to atmospheric frying. ${ }^{6}$ The foremost factors that impact fried products are the frying time-temperature combination of the process; the correct combination is necessary to produce a food product with acceptable physical attributes. ${ }^{1}$ Dueik \& Bouchon $^{6}$ reported that vacuum frying pointedly lowered the final oil content in comparison to atmospheric fried food products and it also significantly reduced the rancidity of the oil used for frying. Most of the benefits from vacuum frying could be attributed to usage of low temperatures $\left(105^{\circ} \mathrm{C}\right)$, the minimal exposure to oxygen, which diminishes the adverse effects on the oil quality. ${ }^{7}$ The process is reported to preserve the natural colour and flavour, ${ }^{8}$ reduce the acrylamide content ${ }^{9}$ and preserve nutritional compounds, such as vitamins and minerals in the fried product. ${ }^{10}$ Vacuum frying has been presented as a good option to achieve high quality food products with better sensory attributes due to the reduced oxidation, reduced frying temperatures and much shorter processing times compared with other techniques. $^{10}$

\section{Disadvantages}

In economic terms, investment cost of vacuum fryers is much higher than conventional fryers, because vacuum frying technique is basically designed for large scale industry. There is a lack of an 
economical vacuum fryer that small scale manufacturers can afford without financial support from external agencies. ${ }^{11}$

\section{Significance of vacuum frying and its benefits in processing of food products}

Oil uptake is one of the vital quality parameters of fried food products, which renders it unsuitable as a healthy food..$^{12}$ The intake of oil and saturated fat has been associated with significant health concerns, including coronary heart disease, cancer, diabetes, and hypertension. ${ }^{13}$ Other unacceptable effects resulting from high temperature frying involved exposure to oxygen are the decrease in nutritive compounds, and the production of toxic molecules in the food or the frying oil. ${ }^{14}$ The low pressure during frying results in fast air diffusion into the porous structure developed during frying. The blocking of oil into the product leads to lower absorption of oil than during atmospheric frying. Vacuum fried carrot slices were found to have approximately $50 \%$ (d.b.) decrease in oil absorption compared to atmospheric fried slices under thermal driving forces of $60^{\circ} \mathrm{C}-80^{\circ} \mathrm{C} .{ }^{15}$

Due to the typical mass transfer phenomenon during vacuum frying, the oil adsorbed to the surface of the fried product (and not in the inner pores of the product as observed in regular atmospheric frying). This necessitates the downstream operation of deoiling which could be achieved by centrifugation or by pressurisation post frying. Moreira et al. ${ }^{16}$ reported a centrifuging system (750rpm for $40 \mathrm{~s}$ ) for deoiling of potato slices fried for 360 s interval in a lab-scale vacuum fryer system $(\mathrm{P}<1.33 \mathrm{kPa})$ at 120,130 , and $140^{\circ} \mathrm{C}$. Non centrifuged samples fried at $120^{\circ} \mathrm{C}$ for the same time had a final oil content of $0.43 \mathrm{~g} / \mathrm{g}$ product compared to $0.097 \mathrm{~g} / \mathrm{g}$ product for the centrifuged samples.

During frying, the oil is exposed to air, water, and heat resulting in thermal, oxidative, and hydrolytic decomposition of the oil. Initially, fats and oils are oxidized to form the primary oxidation products, namely, hydroperoxides. These peroxides are enormously unstable and decompose via fission, leading to the formation of free radicals leads to a variety of chemical products, such as alcohols, aldehydes, ketones, acids, dimers, trimers, polymers, and cyclic compounds. Palm oil, lard, and soybean oil were heated under vacuum at $105^{\circ} \mathrm{C}$ for 20min each hour in an 8-h shift. Results showed that palm oil and lard have greater thermal stability than soybean oil. ${ }^{7}$

Tareke et al. ${ }^{17}$ stated that acrylamide, a genotoxic carcinogen, is generated predominantly in carbohydrate rich food products during high-temperature processes, including frying. Foodstuffs such as French fries, potato chips, and other deep-fat fried, or oven-cooked potato products, including crisp bread, biscuits, crackers, and breakfast cereals analysed for the compound showed high levels of acrylamide. ${ }^{17}$ Mottram et al. ${ }^{18}$ identified asparagine, a major amino acid found in potatoes and cereals, as the key component in the formation of acrylamide which was formed by the Maillard reaction pathway. Vacuum fried potato slices at $118{ }^{\circ} \mathrm{C}$ produced low acrylamide content $(6 \%)$ and desirable yellow golden color and texture attributes compared with those fried in the conventional fryer. ${ }^{9}$

Troncoso et al. ${ }^{19}$ fried pre-treated potato slices at temperatures 120 and $140^{\circ} \mathrm{C}$ under both vacuum $(5.37 \mathrm{kPa}$, absolute pressure) and atmospheric pressure conditions until they reached a final moisture content of $1.8 \mathrm{~kg}$ water $/ 100 \mathrm{~kg}$ (wet basis). The colour of the potato slices fried at atmospheric conditions were described as "darker" and "worst" than the potato slices fried under vacuum. Texture quality was considered "better" for vacuum fried chips and overall quality improved with vacuum frying compared to atmospheric frying.

\section{Heat and mass transfer during vacuum frying}

Yamsaengsung et al. ${ }^{20}$ developed a two-dimensional model to predict the heat and mass transfer phenomena during the vacuum frying of potato chips using the Finite Element toolbox in MATLAB 6.1. They simulated the heat transfer process by integrating convection of heat from the surface to the product, the conduction of heat into the product, and a loss of heat due to evaporation. The mass transfer process was divided into two periods: (1) water loss and (2) oil absorption.

It postulated that during frying operation, the heat from the oil is transmitted to the product surface and is then conducted to the product's centre, resulting in an increased temperature. ${ }^{21}$ Water evaporates as the product temperature reaches the boiling-point temperature. This process is described as a Stephan type heat transfer problem, and attributed to the presence of a moving interface that divides two regions of physical and thermal properties. ${ }^{21}$

Ni \& Datta ${ }^{22}$ developed a multiphase porous media model suitable for studying deep fat frying process since the model encompasses all transport mechanisms such as molecular diffusion, capillary, and pressure driven flow and the properties of the phases (oil, water, vapour, and air) are retained in the model.

Mir-Bel et al. ${ }^{23}$ analysed the effect of temperature and reduced pressure on the convective heat transfer coefficient, $h$. During frying, $h$ changes considerably, reaching a maximum between $700-1600 \mathrm{Wm}^{-2} \mathrm{~K}^{-1}$ in vacuum frying and $800-2000 \mathrm{Wm}^{-2} \mathrm{~K}^{-1}$ in atmospheric frying of food products with different area/volume ratio. The value of $h$ was computed from surface temperature and the results obtained during vacuum frying were compared with those obtained from conventional frying.

Tang Duangdee et al. ${ }^{24}$ stated that the heat transfer coefficient was an important parameter in the modelling and calculating of fryer systems. The significant role of heat flux in the formation and quality of the crunch layer and the development of characteristic properties of the final product such as the colour, texture or flavour has been discussed by Sosa-Morales et al. ${ }^{25}$

Since heat transfer coefficient is dependent on the specific set-up of the system, no one standard method is reported for its determination. Commonly applied methods include measuring the surface temperature of the food product over time and the corresponding water loss. ${ }^{26}$ Alvis et al. ${ }^{27}$ discussed the three methods to compute the convective heat transfer coefficient, namely by steadystate measurement of surface temperature, transient measurement of temperature, and heat flux measurement at the surface.

Pandey \& Moreira, ${ }^{5}$ and Yagua \& Moreira $^{28}$ determined the convective heat coefficient during vacuum frying of potato chips. They found that $h$ changed noticeably as frying proceeded, attaining a maximum between 2200 and $2650 \mathrm{~W} / \mathrm{m}^{2} \mathrm{~K}$. Moreover, it increased with temperature during the initial stages of the frying process and reduced over time. However, the $h$ values obtained were not compared with products fried under atmospheric condition and the effect of vacuum on convective heat transfer during frying was not elucidated in this study. 
Troncoso et al. ${ }^{19}$ determined the kinetics of water loss and oil uptake during frying of pre-treated potato slices under vacuum and atmospheric pressure. The potato slices were fried under vacuum $\left(5.37 \mathrm{kPa}\right.$, absolute pressure, at 120,130 and $\left.140^{\circ} \mathrm{C}\right)$ and atmospheric conditions (at $180^{\circ} \mathrm{C}$ ). The developed two models based on the Fick's law described water loss: (i) with a constant effective diffusive coefficient; and (ii) with a variable effective diffusive coefficient. Moyano \& Berna, ${ }^{29}$ applied Fick's law of diffusion to model the water loss in fried food products with successful settlement between experimental data and calculated values. This model was applied to describe water diffusion in solid foods considering an effective coefficient assumed to include all water transport mechanisms. However, in addition to diffusion, it is expected that water might also be transported through other mechanism like hydrodynamic gradients and capillary flow based on the material structure..$^{30}$ It may be difficult to completely characterise these entire factor using a single effective coefficient of diffusion. Garayo \& Moreira ${ }^{31}$ determined the kinetics of oil absorption in vacuum fried potato slices under different vacuum conditions at different pressures and temperatures, and concluded that oil uptake in final potato chips was affected considerably by the frying temperature and level of vacuum. Tan $\&$ Mittal $^{32}$ stated that donuts fried under vacuum absorbed significantly more oil (14.5-35.8g oil $/ 100 \mathrm{~g}$ dry basis; vacuum levels of 3, 6 and $9 \mathrm{kPa}$ ) compared to the donuts fried at atmospheric conditions (13.1g oil/100g dry basis). This is in contrast to the results reported by other workers crediting vacuum frying with significantly lower oil absorption. ${ }^{15}$

\section{Vacuum cooling}

Vacuum cooling is an advanced cooling technology based on rapic evaporative cooling method for porous and moisture foods. Vacuum cooling has been applied for pre-cooling of horticultural products such as fruits and vegetables to extend their storage life by decreasing post-harvest thermal deterioration. Recent research has been concentrated on the application of vacuum cooling for cooked meats, fishery products and ready to eat meals, for which rapid cooling is beneficial in controlling growth of micro-organisms and preserving quality of the products. Unlike vapour-compression refrigeration, vacuum cooling is based on liquid evaporation to produce a cooling effect, rather than by blowing cold medium over the food product. ${ }^{33}$ Speed and efficiency of vacuum cooling are unsurpassed by any conventional cooling method, especially for boxed or palletised products.

Sun \& Zheng ${ }^{34}$ stated that vacuum cooling is achieved by the rapid evaporation of moisture from the surface as well as within the products. During water evaporation, heat is absorbed into maintain higher energy level to facilitate the molecular movement in gaseous state. The amount of latent eat required is supplied from the product or from the surroundings. The amount of water evaporated is dependent on the surrounding vapour pressure. At a pressure of $1 \mathrm{~atm}$, water evaporates at $100^{\circ} \mathrm{C}$; however, water will boil at lower temperature when the pressure is reduced to below $1 \mathrm{~atm}$.

\section{Vacuum cooling system}

Depending on the application, vacuum cooling system installations vary in size and shape ${ }^{35}$ The basic components consist of a vacuum chamber, vacuum pump, vapour condenser and allied components. In the vacuum chamber, the vacuum pump is used to create vacuum and the food product is sealed airtight and cooled. Various vacuum pumps can be used, but the most commonly used design is the oil-sealed rotary pump. ${ }^{36}$ During vacuum cooling, there will be generation of vapours. For example, a reduction from $72^{\circ} \mathrm{C}$ to $4^{\circ} \mathrm{C}$ is typically associated with a loss of $400-500 \mathrm{~g}$ of moisture, requiring the vacuum pump to handle over $25 \mathrm{~m}^{3}$ of vapour at $22 \mathrm{mbar}^{37} \mathrm{~A}$ vapour condenser is usually installed in the system to condense the vapour to water and discharged through the drain.

\section{Applications of vacuum cooling}

\section{Fruit and vegetables}

Leafy vegetables like spinach and lettuce are ideal candidates for vacuum cooling due to their large surface area to volume ratio being suited for faster evaporation. ${ }^{38,39}$. Lettuce was vacuum cooled prior to PVC film wrapping or post packaging in perforated polypropylene bags..$^{40,41}$ Vacuum cooling successfully reduced lettuce temperature from $25^{\circ} \mathrm{C}$ to $1{ }^{\circ} \mathrm{C}$ within $30 \mathrm{~min} .{ }^{42}$ Lettuce stored at ambient temperature had 3-5 days shelf life, while vacuum cooling in combination with cold storage at $1^{\circ} \mathrm{C}$ was found to prolong shelf life to 14 days. ${ }^{40,41}$

Vacuum cooling for mushroom was found to result in approximately $3.6 \%$ of weight loss, which was greater than $2 \%$ in air blast chilling. ${ }^{43}$ During storage, the vacuum cooled mushroom had less weight loss compared to air blast cooled, compensating for the water loss during cooling. The mushrooms can absorb as much as $6 \%$ of their weight in water if they are wetted for $5 \mathrm{~min}$. therefore; wetting mushrooms before cooling is an effective method to reduce the weight loss during vacuum cooling. Pre-wetting of mushroom before vacuum cooling was reported as an effective method to increase product yield. Vacuum cooling has been accepted commercially in the countries like United States, the United Kingdom, Ireland and other parts of Europe, and has been found to cool mushrooms consistently within a stack. ${ }^{44}$

\section{Cut flowers}

Cut flowers are living tissues and thus their life declines after harvesting due to the physiological changes in respiration, transpiration and biosynthesis, and microbial deterioration during storage, transportation and display. ${ }^{45}$ Post-harvest procedures such as low temperature storage have been found to be effective in extending the vase life of cut-flower. Brosnan \& $\operatorname{Sun}^{45}$ and Sun \& Brosnan ${ }^{46}$ showed that vacuum cooling is effective method to extending the vase life of cut daffodils and cut lily flowers.

\section{Bakery products}

In the bakery industry, it is imperative to cool baked products prior to packaging to avoid in-pack vapour condensation. Vacuum cooling is an effective rapid cooling method for a wide range of baked products such as bread rolls, crusty breads, sausage rolls, pastries, meat pies, biscotti bread, cakes and baked biscuits. ${ }^{47}$ Vacuum cooling is reported to cool baked products from $98^{\circ} \mathrm{C}$ to $30^{\circ} \mathrm{C}$, and results in a weight loss of about $1 \%$ for every $10^{\circ} \mathrm{C}$ drop in temperature or $(6.8 \%$ from $98^{\circ} \mathrm{C}$ to $30^{\circ} \mathrm{C}$ ). In comparison, conventional air blast cooling results in a $3-5 \%$ weight loss depending on air velocity. ${ }^{42}$

\section{Viscous food products}

Viscous food products and components such as sauces, meat slurries, fruit concentrates are challenging to cool by mode of conduction or convection due to the high resistance to heat transfer caused by the high viscosity. Since water is a key component in these products, evaporation of a part of the water could aid in cooling. 
Vacuum cooling has been successfully employed for cooling these products. $^{48}$

\section{Cooked meats}

Under vacuum conditions cooked meat can be cooled from $70-74^{\circ} \mathrm{C}$ to $4^{\circ} \mathrm{C}$ in $1-2.5 \mathrm{~h}$, when compared to $9.4-11.7 \mathrm{~h}$ for air blast cooling, ${ }^{49} 12-14 \mathrm{~h}$ for slow air cooling ${ }^{49}$ and $5-14.3 \mathrm{~h}$ for water immersion cooling. ${ }^{50}$ Sensory analysis showed that panellists preferred vacuum cooled cooked beef because of the natural and intense flavour. ${ }^{44,50}$ However, no significant difference was found between products cooled by vacuum cooling and traditional cooling in terms of overall flavour, texture and acceptability. ${ }^{49,50}$ The physicothermal properties of the vacuum cooled products had low thermal conductivity, thermal diffusivity, specific heat capacity and; apparent density attributed to low moisture content. ${ }^{36}$

\section{Process modelling}

Mathematical models to describe the vacuum cooling process are expected to aid in process design and optimisation. Research on modelling of vacuum cooling process is sparsely reported. ${ }^{51}$ Few models developed for vacuum cooling of liquid food, primarily concentrated on predicting the transient temperature of liquid food and vacuum pressure inside the chamber. ${ }^{48}$ The models were developed based on the assumption that evaporation rate of water was relative to the mass transfer coefficient, mass transfer area and pressure difference between the saturated vapour above liquid surface and the bottom of the vessel. Dostal \& Petera $^{52}$ modified existing models assuming a thermodynamic equilibrium between gas and liquid phases and unsteady heat and mass transfer resistances. During the mathematical modelling of vacuum cooling of cooked meats, Wang \& $\operatorname{Sun}^{43,53}$ developed a model for the vacuum cooling process consisting of two coupled sub models, one for defining the vacuum cooling system and the other for analyzing heat and mass transfer process during cooling of cooked meats.

The first sub-model developed involved analysing the mass conservation of the air and vapour in the system. ${ }^{53}$ The internal air pressure difference was attributed to the pressure of entrance air and air evacuated by the vacuum pump, while vapour generated from water evaporation in the product, vapour removed by the condenser as well as evacuated by the vacuum pump were considered to contribute to total vapour pressure variation.

In the second sub-model, ${ }^{43}$ the heat transfer equation considered was a three-dimensional transient heat conduction problem with inner heat generation. The mass transfer process was treated as hydrodynamic vapour movement through inner pore spaces of the solid product with inner vapour generation. The two sub-models were combined and solved by using finite element method to predict the transient product temperature profile and internal chamber pressure, cooling loss, etc. Experimental verification confirmed that the prediction from the models were relative with experimental measurement. . $^{35,43,53}$

\section{Advantages and disadvantages of vacuum cooling}

McDonald \& Sun ${ }^{44}$ stated that the major advantage of vacuum cooling over other conventional cooling techniques was the short time required to cool a food product to a given temperature. Vacuum cooling has been established as a faster cooling process than conventional methods such as air blast, immersion and still air cooling. The fast rate is attributed to the latent heat involved in evaporation of surface water. ${ }^{44}$ Another advantage of vacuum cooling reported is in its ability to allow uniform cooling of even tightly wrapped products owing to the effect within the whole of the product. ${ }^{54}$ Also, vacuum cooling can be applied on washed product, and also used to remove the surplus moisture present on the surface of the product. ${ }^{55}$

McDonald \& Sun ${ }^{44}$ discussed the major disadvantage of vacuum cooling as the loss of weight due to moisture removal. The high equipment cost for vacuum cooling process, limits the type of products suited to this method (large surface area products), and the additional cold store requirement to keep product cool are disadvantageous. ${ }^{56}$

\section{Vacuum drying}

Thirugnanasambandham \& Sivakumar, ${ }^{57}$ applied vacuum drying process and studied the moisture removal, vitamin $\mathrm{C}$ content and total dietary fibre in coriander leaves during the drying process. Experiments were conducted as per the Box-Behnken design (BBD) and Response Surface Methodology (RSM) was applied to estimate and optimize the three key drying parameters, namely temperature, loading rate and the level of vacuum. The optimal conditions were found to be temperature of $75^{\circ} \mathrm{C}$, loading rate of $0.63 \mathrm{~kg} / \mathrm{m}^{2}$ and vacuum of $28 \mathrm{mmHg}$.

Watanawanyoo \& Chaitep, ${ }^{58}$ studied the possibility of applying a vacuum drying system operated by water ejector pump to dry agricultural products commercially. They examined the influence of operating variables on the performance of the water ejector pump to identify the best point for drying. The influence of four dependent variables, i.e. vacuum, temperature, water pressure and quantity of make-up air was evaluated on the drying performance.

Sumic et al. ${ }^{59}$ optimized the vacuum-drying process for frozen sour cherries with a view to preserve the "phytochemicals" and textural attributes. The range of parameters evaluated includes temperature $\left(46-74^{\circ} \mathrm{C}\right)$ and vacuum $(17-583 \mathrm{mbar})$. The quality of the dried sour cherry was quantified in terms of the total solids, water activity, total phenolics, vitamin $\mathrm{C}$, antioxidant activity, anthocyanin content, total colour change and firmness. The optimised conditions obtained in the study for vacuum drying of sour cherry were $54.03^{\circ} \mathrm{C}$ and $148.16 \mathrm{mbar}$.

Bazyma et al. ${ }^{60}$ theoretically and experimentally evaluated low-temperature vacuum drying processes for floral agriculture products. They combined the system with Infrared ceramic radiators and analysed the efficient radiator power to provide optimal drying conditions in terms of the drying period, energy consumed and quality of the dried product. Jena \& Das ${ }^{61}$ applied a laboratory scale vacuum dryer to dry coconut press cake to a moisture content less than $0.02 \%$ (dry basis). The drying characteristics of the process were also examined under varying thickness of the press cake $(2,3$ and $4 \mathrm{~mm})$ and vacuum chamber plate temperature $\left(65,70\right.$ and $\left.75^{\circ} \mathrm{C}\right)$ at $65 \mathrm{mmHg}$ absolute pressure.

Jaya \& Das $^{62}$ vacuum dried mango pulp spread to varying thickness $(2,3$ and $4 \mathrm{~mm})$ and chamber plate temperature $(65,70$, and $75^{\circ} \mathrm{C}$ ) under $30-50 \mathrm{~mm}$ of mercury absolute pressure. A model based on moisture diffusivity was applied and a close agreement between predicted and experimental moisture content of the pulp was observed. It was recommended that vacuum drying of coconut press cake should be carried at maximum pulp thickness of $2.6 \mathrm{~mm}$ and vacuum chamber plate temperature of $72.3^{\circ} \mathrm{C}$. 


\section{Microwave Vacuum Drying (MWV Drying)}

Drying is amongst the earliest applications in food processing for which vacuum was adopted and extensively reviewed in literature. The combination of two novel technologies, viz., microwave and vacuum has been also been reported. Microwave-vacuum drying has been examined as a prospective method for obtaining highquality dried foodstuffs, including fruits, vegetables and grains. ${ }^{63-65}$ It combines the advantages of both vacuum drying and microwave drying resulting in higher drying rates, lower temperatures $\left(25-50^{\circ} \mathrm{C}\right)$ and uniform energy efficiency compared to other drying methods. ${ }^{66}$ The input energy dissipates in the product, and the moisture within adjusts automatically. The combined process results in superior sensory quality including aroma and flavour profile and preservation of color in dried products. Cui et al ${ }^{67}$ used MWV drying to obtaining high-quality dried honey. Liquid honey was first heated and then dehydrated in a MWV dryer to a final moisture content less than $2.5 \%$ within $10 \mathrm{~min}$. The drying curves and the temperature changes of samples were established during MWV drying at different vacuum pressure levels, microwave power and sample thicknesses.

Drouzas et al. ${ }^{68}$ developed a laboratory microwave vacuum drier to conduct kinetic experiments drying of model fruit gels simulating orange juice concentrate. The system was operated in the vacuum range of $30 \pm 50$ mbar and microwave power of $640-710 \mathrm{~W}$. The distribution of the electromagnetic field was determined from the drying rate of samples, placed at 5 different locations.

Drouzas et al. ${ }^{69}$ applied microwave vacuum dying to banana slices and reported that this method of drying was preferable over conventional dying techniques. The drying standardised introduced pulse generated microwave power in banana samples. Mousa \& Farid ${ }^{70}$ studied vacuum drying on banana slices in a domestic microwave oven. The results indicated that banana temperature increased uniformly and rapidly to the saturation water vapour temperature equivalent to the vacuum used followed by a slow rise until most of the free moisture was removed. The thermal and drying efficiencies were found to fall from initial values of $100 \%$ to as low as $30-40 \%$ towards the end of drying. Both efficiencies were found to surge with the use of vacuum, especially at low moisture content..$^{71}$

Yongsawatdigul \& Gunasekaran ${ }^{72}$ investigated MWV drying on cranberries pre-treated for $24 \mathrm{~h}$ before drying in a laboratory-scale microwave-vacuum dryer operating in continuous or pulsed mode. In the continuous mode, two levels of microwave power $(250,500 \mathrm{~W})$ in combination with two levels of absolute pressure $(5.33,10.67 \mathrm{kPa})$ were applied. Microwave power of $250 \mathrm{~W}$ and two levels of pressure $(5.33,10.67 \mathrm{kPa})$ with two levels of power-on time $(30,60 \mathrm{~s})$ and three levels of power-off time $(60,90,150 \mathrm{~s})$ were used in the pulsed mode.

Microwave application in combination with vacuum is reported to produce heating rates about 20-30times higher than conventional freeze-drying. Commercially, microwave drying is ranked between spray drying and freeze-drying. The capital investment involved for MWV drying is higher (about 60\%) than that of freeze drying equipment, but the operating cost is reported to be reduced by a factor of 3 to 4 , because of the higher solids content of the concentrate..$^{73,74}$

\section{Vacuum packaging}

In addition to processing applications, vacuum has also been adopted during packaging of food products to extend its shelf life.
The process involved evacuating the headspace from the package and sealing the package in a leak-proof and airtight manner. The technique has been adopted for a wide variety of food products including whole, cut and processed items such as meat. Stamatis \& Arkoudelos ${ }^{75}$ established the beneficial effect of vacuum ${ }^{76}$ and modified atmospheres packaging $\left(50 \% \mathrm{CO}_{2} / 50 \% \mathrm{~N}_{2}\right)$ initial head-spaces in comparison with atmospheric air packages on the microbiological, physicochemical and sensory variations of chub mackerel (Scombercoliasjaponicus) stored at 3 and $6^{\circ} \mathrm{C}$. Frangos et al. ${ }^{77}$ assessed the effect of vacuum packaging in combination with other ingredients such as salt, oregano, essential oil on fresh rainbow trout fillets stored at $4^{\circ} \mathrm{C}$. The treatments were evaluated in terms of the chemical and microbial quality of fresh product and sensory evaluation of the cooked trout. The study established the efficacy of vacuum packaging in extending the shelf life of the trout samples while preserving the freshness of the produce.

Hansen et al $^{78}$ examined the effect of vacuum packaging in combination with a $\mathrm{CO}_{2}$ emitter pad on the shelf life of cod loins (farmed Atlantic cod, Gadusmorhua). The packaged samples were stored at $2{ }^{\circ} \mathrm{C}$ and drawn at an interval of 15 days and the treatment effects were evaluated for bacterial growth, microbiota and sensory quality. The study observed that vacuum packaging had a positive effect on the shelf life of the samples. ${ }^{79}$

Narasimha \& Sachindra ${ }^{80}$ used vacuum packaging (VP) and modified atmospheric packaging (MAP) to preserve meat and poultry products. MAP was observed to retain the meat colour better than in VP establishing the necessity of oxygen to project the right colour of myoglobin in meat. The observation was further confirmed since it was reported that the meat colour was recovered when removed from VP packets and exposed to air. The microbial profiles for products packed in using MAP and VP were not significantly different. ${ }^{81-90}$

\section{Conclusion}

Vacuum technology has been applied in conjunction with food processing unit operations such as frying, cooling, drying and packaging to reap several benefits such as improved product quality and nutritive value, extended shelf life and faster processing. The adoption of vacuum technology is limited by the additional capital cost and requirement for leak proof systems. The future direction for the technology includes exploration of further avenues for its application and developments to make the vacuum systems economical and more energy efficient. Such development would result in widespread adoption of the technology for sustainable and economically viable processing applications.

\section{Acknowledgements}

None.

\section{Conflict of interest}

The author declares that there is none of the conflicts.

\section{References}

1. Andrés-Bello A, García-Segovia P, Martínez-Monzó J. Vacuum frying: An alternative to obtain high-quality dried products. Food Engineering Reviews. 2011;3(2):63-78.

2. Yamsaengsung R, Ariyapuchai T, Prasertsit K. Effects of vacuum frying on structural changes of bananas. Journal of Food Engineering. 2011;106(4):298-305. 
3. Sothornvit R. Edible coating and post-frying centrifuge step effect on quality of vacuum-fried banana chips. Journal of Food Engineering. 2011;107(3-4):319-325.

4. Diamante LM, Savage GP, Vanhanen L. Optimisation of vacuum frying of gold kiwifruit slices: application of response surface methodology. International Journal of Food Science \& Technology. 2012;47(3):518-524.

5. Pandey A, Moreira RG. Batch vacuum frying system analysis for potato chips. Journal of Food Process Engineering. 2012;35(6):863-873.

6. Dueik V, Bouchon P. Development of healthy low-fat snacks: understanding the mechanisms of quality changes during atmospheric and vacuum frying. Food reviews international. 2011;27(4):408-432.

7. Shyu SL, Hau LB, Hwang LS. Effect of vacuum frying on the oxidative stability of oils. Journal of the American Oil Chemists' Society. 1998;75(10):1393-1398.

8. Shyu SL, Hwang LS. Effects of processing conditions on the quality of vacuum fried apple chips. Food Research International. 2001;34(2-3):133-142.

9. Granda C, Moreira RG, Tichy SE. Reduction of acrylamide formation in potato chips by low-temperature vacuum frying. Journal of Food Science. 2004;69(8):E405-E411.

10. Da Silva PF, Moreira RG. Vacuum frying of high-quality fruit and vegetable-based snacks. LWT-Food Science and Technology. 2008;41(10):1758-1767.

11. Inprasit C. Scale up of vacuum fryer for Durian. Research Report. The Thailand Research Fund; 2003.

12. Bouchon P, Pyle DL. Modelling oil absorption during post-frying cooling: I: model development. Food and Bioproducts processing. 2004;83(4):253-260.

13. Saguy IS, Dana D. Integrated approach to deep fat frying: engineering, nutrition, health and consumer aspects. Journal of food engineering. 2003;56(2):143-152.

14. Fillion L, Henry CJK. Nutrient losses and gains during frying: a review. International journal of food sciences and nutrition. 1998;49(2):157-168.

15. Dueik V, Robert P, Bouchon P. Vacuum frying reduces oil uptake and improves the quality parameters of carrot crisps. Food Chemistry. 2010;119(3):1143-1149.

16. Moreira RG, Da Silva PF, Gomes C. The effect of a de-oiling mechanism on the production of high quality vacuum fried potato chips. Journal of Food Engineering. 2009;92(3): 297-304.

17. Tareke E, Rydberg P, Karlsson P, et al. Acrylamide: a cooking carcinogen? Chemical research in toxicology. 2000;13(6):517-522.

18. Mottram DS, Wedzicha BL, Dodson AT. Food chemistry: acrylamide is formed in the Maillard reaction. Nature. 2002;419(6906):448-449.

19. Troncoso E, Pedreschi F, Zuniga RN. Comparative study of physical and sensory properties of pre-treated potato slices during vacuum and atmospheric frying. LWT-Food Science and Technology. 2009;42(1):187-195.

20. Yamsaengsung R, Rungsee C, Prasertsit K. Simulation of the heat and mass transfer processes during the vacuum frying of potato chips. Songklanakarin Journal of Science and Technology. 2008;30(1):109-115.

21. Farkas BE, Singh RP, Rumsey TR. Modeling heat and mass transfer in immersion frying. I, model development. Journal of food Engineering. 1996;29(2):211-226.

22. Ni H, Datta AK. Moisture, oil and energy transport during deep-fat frying of food materials. Food and Bioproducts processing. 1999;77(3):194-204.
23. Mir-Bel J, Oria R, Salvador ML. Influence of temperature on heat transfer coefficient during moderate vacuum deep-fat frying. Journal of food engineering. 2012;113(2):167-176.

24. Tangduangdee C, Bhumiratana S, Tia S. Heat and mass transfer during deep-fat frying of frozen composite foods with thermal protein denaturation as quality index. Science Asia. 2003;29:355-364.

25. Sosa-Morales ME, Orzuna-Espíritu R, Vélez-Ruiz JF. Mass, thermal and quality aspects of deep-fat frying of pork meat. Journal of Food Engineering. 2006;77(3):731-738.

26. Costa RM, Oliveira FA, Delaney O, et al. Analysis of the heat transfer coefficient during potato frying. Journal of Food Engineering. 1999;39(3):293-299.

27. Alvis A, Vélez C, Rada-Mendoza M, et al. Heat transfer coefficient during deep-fat frying. Food Control. 2009;20(4):321-325.

28. Yagua CV, Moreira RG. Physical and thermal properties of potato chips during vacuum frying. Journal of Food Engineering. 2011;104(2):272-283.

29. Moyano PC, Berna AZ. Modeling water loss during frying of potato strips: Effect of solute impregnation. Drying Technology. 2002;20(7):1303-1318.

30. Saravacos GD, Maroulis ZB. Transport properties of foods. CRC Press; 2001;

31. Garayo J, Moreira R. Vacuum frying of potato chips. Journal of Food Engineering. 2002;55(2):181-191.

32. Tan KJ, Mittal GS. Physicochemical properties changes of donuts during vacuum frying. International Journal of Food Properties. 2006;9(1):85-98.

33. Mellor JD. Vacuum techniques in the food industry [review]. Food Technology in Australia. 1982.

34. Sun DW, Zheng L. Vacuum cooling technology for the agri-food industry: Past, present and future. Journal of Food Engineering. 2006;77(2):203-214.

35. Wang L, Sun DW. Rapid cooling of porous and moisture foods by using vacuum cooling technology. Trends in Food Science \& Technology. 2001;12(5-6):174-184.

36. Mc Donald K, Sun DW, Lyng JG. Effect of vacuum cooling on the thermo physical properties of a cooked beef product. Journal of Food Engineering. 2002;52(2):167-176.

37. Mc Donald K, Sun DW. Effect of evacuation rate on the vacuum cooling process of a cooked beef product. Journal of Food Engineering. 2001;48(3):195-202.

38. Harvey JM. Improved techniques for vacuum cooling vegetables. ASHRAE J. 1963;5(11):41-44.

39. Shewfelt RL. Postharvest treatment for extending the shelf life of fruits and vegetables. Food technology. 1986.

40. Artes F, Martinez JA. Effects of vacuum cooling and packaging films on the shelf life of salinas lettuce. Science et Technique du Froid. 1994.

41. Artés F, Martinez JA. Influence of packaging treatments on the keeping quality of 'Salinas' lettuce. LWT-Food Science and Technology. 1996;29(7):664-668.

42. Everington DW. Vacuum technology for food processing. Food technology international Europe. 1993;71-74.

43. Wang L, Sun DW. Modelling vacuum cooling process of cooked meat-part 2: mass and heat transfer of cooked meat under vacuum pressure. International Journal of Refrigeration. 2002;25(7):862-871.

44. Mcdonald K, Sun DW. Vacuum cooling technology for the food processing 
industry: a review. Journal of food engineering. 2000;45(2):55-65.

45. Brosnan T, Sun DW. PH-Postharvest Technology: Compensation for water loss in vacuum-precooled cut lily flowers. Journal of agricultural engineering research. 2001;79(3):299-305.

46. Sun DW, Brosnan T. Extension of the vase life of cut daffodil flowers by rapid vacuum cooling. International Journal of Refrigeration. 1999;22(6):472-478

47. Anon. It's cooler to work with a vacuum. Food Manufacture. 2004;53-54

48. Houska M, Podloucký S, Žitný R, et al. Mathematical model of the vacuum cooling of liquids. Journal of Food Engineering. 1996; 29(3-4):339-348.

49. Desmond EM, Kenny TA, Ward P, et al. Effect of rapid and conventional cooling methods on the quality of cooked ham joints. Meat Science. 2000;56(3):271-277.

50. Mc Donald Karl, Sun DW. Pore size distribution and structure of a cooked beef product as affected by vacuum cooling. Journal of food process engineering. 2001;24(6):381-403

51. Wang L, Sun DW. Recent developments in numerical modelling of heating and cooling processes in the food industry-a review. Trends in Food Science \& Technology. 2003;4(10):408-423.

52. Dostal M, Petera K. Vacuum cooling of liquids: mathematical model. Journal of food engineering. 2003;61(4):533-539.

53. Wang L, Sun DW. Modelling vacuum cooling process of cooked meatpart 1: analysis of vacuum cooling system. International Journal of Refrigeration. 2002;25(7):854-861

54. Noble R. A review of vacuum cooling of mushrooms. Mushroom Journal. 1985;149:168-170.

55. Longmore AP. Vacuum cooling of food products. Chemical Processing. 1971;2:7-18.

56. Longmore AP. The pros and cons of vacuum cooling. Food Industries of South Africa. 1973;26(6-7):9-11.

57. Thirugnanasambandham K, Sivakumar V. Enhancement of shelf life of Coriandrumsativum leaves using vacuum drying process: Modeling and optimization. Journal of the Saudi Society of Agricultural Sciences. 2014;15(2):195-201

58. Watanawanyoo P, Chaitep S. Performance evaluation of a water ejection type in vacuum drying system. Energy Procedia. 2014;52:588-597.

59. Šumić Z, Tepić A, Vidović S, et al. Optimization of frozen sour cherries vacuum drying process. Food chemistry. 2013;36(1):55-63.

60. Bazyma LA, Guskov VP, Basteev AV, et al. The investigation of low temperature vacuum drying processes of agricultural materials. Journal of Food Engineering. 2006;74(3):410-415.

61. Jena S, Das H. Modelling for vacuum drying characteristics of coconut press cake. Journal of Food Engineering. 2007;79(1):92-99.

62. Jaya S, Das H. A vacuum drying model for mango pulp. Drying technology. 2003;21(7):1215-1234.

63. Cui ZW, Xu SY, Sun DW. Dehydration of garlic slices by combined microwave-vacuum and air drying. Drying technology. 2003;21(7):1173-1184

64. Cui ZW, Xu SY, Sun DW. Effect of microwave-vacuum drying on the carotenoids retention of carrot slices and chlorophyll retention of Chinese chive leaves. Drying Technology. 2004;22(3):563-575.

65. Cui ZW, Xu SY, Sun DW. Microwave-vacuum drying kinetics of carrot slices. Journal of Food Engineering. 2004;65(2):157-164.

66. Durance TD, Wang JH. Energy consumption, density, and rehydration rate of vacuum microwave-and hot-air convection-dehydrated tomatoes. Journal of Food Science. 2002;67(6):2212-2216.

67. Everington DW. Vacuum technology for food processing. Food technology international Europe. 1993;71-74.

68. Cui ZW, Sun LJ, Chen W, et al. Preparation of dry honey by microwavevacuum drying. Journal of Food Engineering. 2008;84(4):582-590.

69. Drouzas AE, Tsami E, Saravacos GD. Microwave/vacuum drying of model fruit gels. Journal of Food Engineering. 1999;39(2):117-122.

70. Drouzas AE, Schubert H. Microwave application in vacuum drying of fruits. Journal of food Engineering. 1996;28(2):203-209.

71. Mousa N, Farid M. Microwave vacuum drying of banana slices. Drying Technology. 2002;20(10):2055-2066.

72. Dincer I, Yildiz M. Modelling of thermal and moisture diffusions in cylindrically shaped sausages during frying. Journal of Food Engineering. 1996;28(1):35-44

73. Yongsawatdigul J, Gunasekaran S. Microwave-vacuum drying of cranberries: part ii. Quality evaluation. Journal of Food Processing and Preservation. 1996;20(2):145-156.

74. Attiyate Y. Microwave vacuum drying-1st industrial application. Food Engineering. 1979;51(2):78-79.

75. Thuery J. Microwaves: industrial, scientific, and medical applications. USA: Artech House on Demand; 1992

76. Stamatis N, Arkoudelos J. Quality assessment of Scombercoliasjaponicus under modified atmosphere and vacuum packaging. Food Control. 2007;18(4):292-300.

77. Dueik V, Bouchon P. Vacuum frying as a route to produce novel snacks with desired quality attributes according to new health trends. Journal of food science. 2011;76(2):E188-E195.

78. Frangos L, Pyrgotou N, Giatrakou V. Combined effects of salting, oregano oil and vacuum-packaging on the shelf-life of refrigerated trout fillets. Food microbiology. 2010;27(1):115-121.

79. Hansen AÅ, Moen B, Rødbotten M, et al. Effect of vacuum or modified atmosphere packaging (MAP) in combination with a $\mathrm{CO} 2$ emitter on quality parameters of cod loins (Gadusmorhua). Food Packaging and Shelf Life. 2016;9:29-37.

80. Houska M, Podloucký S, Žitný R, et al. Mathematical model of the vacuum cooling of liquids. Journal of Food Engineering. 1996;29(3):339-348.

81. Narasimha Rao D, Sachindra NM. Modified atmosphere and vacuum packaging of meat and poultry products. Food Reviews International. 2002;18(4):263-293.

82. Malpas EW. Vacuum equipment for evaporative cooling. Process Biochemistry. 1972;7(10):15.

83. Mc Donald K, Sun DW. The formation of pores and their effects in a cooked beef product on the efficiency of vacuum cooling. Journal of Food Engineering. 2001;47(3):175-183.

84. Mc Donald K, Sun DW, Kenny T. The effect of injection level on the quality of a rapid vacuum cooled cooked beef product. Journal of Food Engineering. 2001;47(2):139-147.

85. Roca E, Broyart B, Guillard V, et al. Predicting moisture transfer and shelf-life of multi domain food products. Journal of Food Engineering. 2008;86(1):74-83.

86. Roca E, Guillard V, Broyart B, et al. Effective moisture diffusivity modelling versus food structure and hygroscopicity. Food chemistry. 2008;106(4):1428-1437. 
87. Shyu SL, Hau LB, Hwang LS. Effect of vacuum frying on the oxidative stability of oils. Journal of the American Oil Chemists Society. 1998;75(10):1393-1398.

88. Stamatis N, Arkoudelos JS. Effect of modified atmosphere and vacuum packaging on microbial, chemical and sensory quality indicators of fresh, filleted Sardinapilchardus at $3^{\circ} \mathrm{C}$. Journal of the Science of Food and Agriculture. 2007;87(6):1164-1171
89. Tan KJ, Mittal GS. Physicochemical properties changes of donuts during vacuum frying. International Journal of Food Properties. 2006;9(1):85-98.

90. Yongsawatdigul J, Gunasekaran S. Microwave-vacuum drying of cranberries: Part I. Energy use and efficiency. Journal of Food Processing and Preservation. 1996;20(2):121-143. 